\title{
Usage of tilt-in-space, recline, and elevation seating functions in natural environment of wheelchair users
}

\author{
Dan Ding, PhD $;^{1-2 *}$ Elizabeth Leister, MS; ${ }^{1-2}$ Rory A. Cooper, PhD; ${ }^{1-4}$ Rosemarie Cooper, MPT, ATP; ${ }^{1-2}$ \\ Annmarie Kelleher, MS, OTR/L, ATP; ${ }^{1-2}$ Shirley G. Fitzgerald, PhD $;^{1-2}$ Michael L. Boninger, MD $^{1-4}$ \\ ${ }^{1}$ Department of Rehabilitation Sciences and Technology, School of Health and Rehabilitation Sciences, University of \\ Pittsburgh, Pittsburgh, PA; ${ }^{2}$ Human Engineering Research Laboratories, Department of Veterans Affairs Pittsburgh \\ Healthcare System, Pittsburgh, PA; ${ }^{3}$ Department of Physical Medicine and Rehabilitation, School of Medicine, and \\ ${ }^{4}$ Department of Bioengineering, Swanson School of Engineering, University of Pittsburgh, Pittsburgh, PA
}

\begin{abstract}
This study examined the usage of powered seating functions, including tilt-in-space, backrest recline, and seat elevation, among a group of wheelchair users during their typical daily activities. Twelve individuals who used a power wheelchair with seating functions participated in the study. They drove their own wheelchair and used the seating functions as needed in their community environment for about 2 weeks while the seating function usage was recorded with a portable device. We found that subjects occupied their wheelchair for $11.8+/-3.4$ hours a day (all data shown as mean +/- standard deviation). While occupying their wheelchairs, they accessed tilt-in-space, backrest recline, and seat elevation $19+/-14$ times a day for $64.1 \%+/-36.8 \%, 12+/-8$ times for $76.0 \%+/-$ $29.8 \%$, and $4+/-4$ times for $22.5 \%+/-34.9 \%$, respectively. Subjects chose to stay in tilted and reclined positions in their wheelchair for $39.3 \%+/-36.5 \%$ of their time each day. They spent little time in a fully upright position. Subjects changed their seating positions every $53.6+/-47.0$ minutes. Time spent in positions of different seating pressures varied among subjects. The information collected could enhance clinical practice of wheelchair provision, resulting in better compliance with clinical instructions and appropriate use of seating functions among wheelchair users.
\end{abstract}

Key words: backrest recline, data logging, posture, pressure ulcer, rehabilitation, seat elevator, seating posture, tilt-in-space, usage pattern, wheelchair, wheelchair prescription.

\section{INTRODUCTION}

Prescribing seating for individuals who use wheelchairs primarily for mobility often entails considering posture, comfort, function, and pressure management [1]. Power wheelchairs with self-actuated seating functions, such as tilt-in-space, backrest recline, and seat elevation, are usually prescribed by clinicians to facilitate posture change and/or assist activities of daily living (ADL) for persons with a high-level spinal cord injury (SCI) who have impaired sensation and are unable to adjust postures independently or for those with neuromotor impairments who are unable to use a standard wheelchair seat [1-3].

\footnotetext{
Abbreviations: $\mathrm{ADL}=$ activities of daily living, $\mathrm{ANOVA}=$ analysis of variance, CAT = Center for Assistive Technology, $\mathrm{CP}=$ cerebral palsy, FSA $=$ Force Sensitive Applications, FSR $=$ force-sensing resistor, HERL $=$ Human Engineering Research Laboratories, ICC $=$ intraclass correlation coefficient, MS = multiple sclerosis, RESNA = Rehabilitation Engineering and Assistive Technology Society of North America, SCI = spinal cord injury, SD = standard deviation, SFDL = seating function data logger, VA = Department of Veterans Affairs.

* Address all correspondence to Dan Ding, PhD; HERL, VA Pittsburgh Healthcare System, 7180 Highland Dr, Bldg 4, 2d Fl East, 151R1-H, Pittsburgh, PA 15206; 412-365-4850; fax: 412-365-4858. Email: dad5@pitt.edu

DOI: $10.1682 / J R R D .2007 .11 .0178$
} 
Previous research that evaluated the effectiveness of tilt-in-space and backrest recline functions was largely conducted in laboratory settings. Studies have been conducted to examine seat pressures at different angles of tilt-in-space and backrest recline [4-7]. Researchers found that tilt-in-space significantly reduced static seating pressure, a key component in pressure ulcer development [8], and that combining tilt-in-space with backrest recline reduced pressure more than tilt-in-space alone $[4,6]$. In addition, almost all the previous laboratorybased studies suggested that persons use large tilt-inspace and recline angles to effectively manage pressure to reduce the risk of skin breakdown $[4,7,9]$. The study concluded that the biggest reduction in maximum pressure at the ischial tuberosities was found at $45^{\circ}$ of tilt-inspace and $120^{\circ}$ of backrest recline and that an effective weight shift could be achieved only when tilt-in-space is $>15^{\circ}$ [4]. As for the time required for pressure relief, Coggrave and Rose described measuring transcutaneous oxygen tension to effectively determine when pressure relief becomes adequate [10]. They measured the time taken for subjects to return their tissue oxygen to unloaded levels and found that brief pressure lifts for 15 to 30 seconds did not relieve pressure for most people, while longer lifts for an average of 111 seconds were required to return tissue oxygen to unloaded levels.

In addition to facilitating appropriate pressure management, tilt-in-space and backrest recline may also improve seating comfort [11]. Although comfort is difficult to define and measure, it is a very real concern in seating. Feelings of discomfort among wheelchair users can have serious consequences, including equipment abandonment, decreased satisfaction, and an inability to function throughout the day [12]. Previous studies have shown that high peak pressures at the body-seat interface correlated with seating discomfort [13-14]. Qualitative research has also been undertaken with respect to seating and comfort. A Wheelchair Seating Discomfort Assessment Tool (a survey questionnaire) was developed to quantify seating discomfort in wheelchair users who have intact sensation in the buttocks [12].

Rehabilitation Engineering and Assistive Technology Society of North America (RESNA) recently published a position paper on the application of seat-elevating devices for wheelchair users for whom seat elevation is considered medically necessary [2]. This feature can help wheelchair users accomplish mobility-related ADL, such as performing transfers and reaching objects at different heights to preserve upper-limb functions and to achieve eye-to-eye contact in social situations [2,15].

Only a few studies have investigated real-life usage of such powered seating functions in the natural environment of wheelchair users [11,16-18]. In a survey study by Lacoste et al. [11], they found that 97.5 percent of respondents used their tilt-in-space and/or recline systems every day. About 70 percent reported using the system primarily to rest, relax, increase comfort, and decrease pain. Surprisingly, a minority ( $\leq 35 \%)$ reported using the system for preventing skin redness and/or pressure sores. Small and middle angles were used more often than large angles. A few other studies used portable devices to monitor the use of tilt-in-space wheelchairs [16-17]. They reported that data collection failed because of the difficulty of device installation and associated reliability issues [16]. Ten subjects with tilt-in-space wheelchairs were found to use this function $16 \pm 10$ times a day [17], but the usage of other seating functions was not examined (all data shown as mean \pm standard deviation [SD] unless otherwise noted).

The objective of this study was to use a portable seating function data logger (SFDL) to examine how individuals used self-actuated seating functions such as tilt-inspace, backrest recline, and seat elevation during typical ADL. The information collected allowed for a novel and quantitative description of the usage characteristics of such seating functions. Three of our specific aims were to-

1. Quantify the natural usage patterns of three self-actuated seating functions (tilt-in-space, backrest recline, and seat elevation) by calculating access frequencies and access durations to each seating function.

2. Investigate the characteristics of such usage patterns by calculating the percentage of time spent in positions of low, intermediate, and high peak pressures, and the repositioning rate.

3. Explore whether participants' perceived usage was consistent with the SFDL actual recorded usage.

\section{METHODS}

\section{Subjects}

Subjects were recruited through mailings to power wheelchair users in the Human Engineering Research Laboratories (HERL) wheelchair user registry [19] and through therapists working at the Center for Assistive Technology (CAT) at the University of Pittsburgh. 
Subjects were included in the study if they (1) were between the ages of 18 and 70; (2) used a power wheelchair equipped with functioning tilt-in-space, backrest recline, and/or seat elevation; and (3) were able to independently control the seating functions. Individuals were ineligible to participate if they had open pressure sores. Because this was a pilot study and no prior information on the natural usage of powered seating functions was available, we did not perform a power analysis to determine the sample size. A total of 12 subjects were recruited to participate in the study, and results are reported for 11 subjects.

\section{Instrumentation}

An SFDL was developed to record the usage of selfactuated seating functions, including tilt-in-space, backrest recline, and seat elevation. It consists of a commercial programmable data logger from Onset Computer Corp (Bourne, Massachusetts), three tilt sensors from Crossbow Technologies Inc (San Jose, California), three forcesensing resistors (FSRs) from Interlink Electronics, Inc (Camarillo, California), and one linear position transducer from Unimeasure Inc (Corvallis, Oregon). The SFDL (Figure 1) is a modular system that can be mounted on a variety of power wheelchairs without additional modifications to the wheelchair and does not interfere with ADL of wheelchair users.

The solid-state analog tilt sensors that we used in the study have an angular range of $\pm 75^{\circ}$ with respect to gravity with a resolution of $0.05^{\circ}$ and sensitivity around $2.0 \mathrm{~V} / \mathrm{rad}$. The tilt sensor outputs were also compared with the digital protractor outputs in 30 trials, and the average difference was $0.44^{\circ} \pm 0.17^{\circ}$. The three tilt sensors were attached to the wheelchair base, the seat pan, and the backrest, respectively. We used the base sensor to eliminate the effect of slopes in calculating the tilt-inspace and backrest recline angles. The tilt-in-space angle was calculated as the angle between the seat and the driving surface. The backrest sensor, mounted to the wheelchair through a bracket, was oriented roughly parallel to the ground, and the backrest recline angle was calculated as the angle between the seat and backrest.

We used three FSRs to detect wheelchair occupancy. One FSR was attached to the seat pan underneath the cushion where one of the subject's ischial tuberosities would approximately rest, and the other two FSRs were affixed where the subject's thighs would rest. To reliably

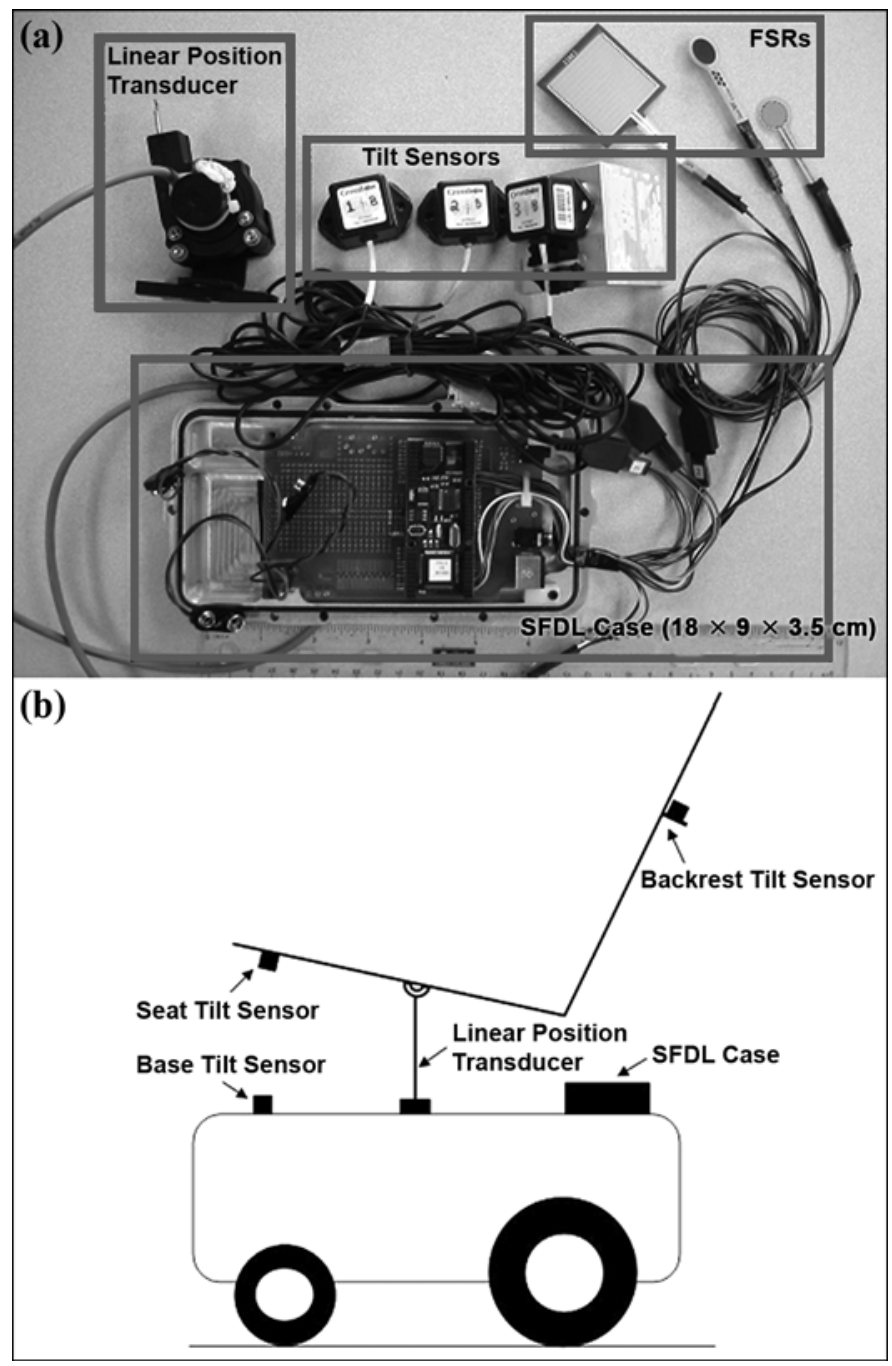

Figure 1.

(a) Seating function data logger (SFDL) and (b) sensor placement. FSR $=$ force-sensing resistor.

detect wheelchair occupancy, we adjusted and tested the sensitivity of each FSR before data collection.

We used the linear position transducer with a $50 \mathrm{~cm}$ linear range to measure seat elevation. The outputs were also compared with the measurements from a ruler in 30 trials, and the average difference was $0.06 \pm$ $0.05 \mathrm{~cm}$. The swivel base of the transducer was attached to the wheelchair base and the wire rope to a location underneath the seat on the wheelchair frame. The attachment point was chosen such that the wire rope exited perpendicular to the linear transducer and the transducer was not activated when tilt-in-space or backrest recline was used. 


\section{Protocol}

The protocol was approved by institutional review boards at the Department of Veterans Affairs (VA) Pittsburgh Healthcare System and the University of Pittsburgh. The nature of the study was explained and written informed consent was obtained from all subjects before data collection.

We completed a descriptive study to assess the objectives of the research. Subject testing was conducted at one of three locations:

1. The HERL, located at the Highland Drive, VA Pittsburgh Healthcare System.

2. The CAT, located on the University of Pittsburgh campus.

3. The participant's home.

\section{First Visit}

After obtaining informed consent, we collected demographic information from subjects, including age, sex, type of disability, wheelchair make and model, wheelchair age, cushion type, ranges of tilt-in-space and backrest recline angles, and seat elevation. Subjects were then transferred out of their wheelchairs with appropriate clinical assistance, and the SFDL pressure sensors were attached to the seat pan.

Before subjects were transferred back to their wheelchairs, the FSA (Force Sensitive Applications) Pressure Mapping System from Vista Medical Ltd (Winnipeg, Canada) was placed on top of the wheelchair cushion for a pressure-mapping procedure. The procedure began with the wheelchair "fully upright." A fully upright position was defined at a tilt-in-space angle between $0^{\circ}$ and $2.5^{\circ}$ and a recline angle between $90^{\circ}$ and $95^{\circ}$. During the procedure, each subject was asked to access the full range of tilt-in-space and recline angles in $5^{\circ}$ increments. The FSA Pressure Mapping System recorded peak pressure readings at these combined tilt-in-space and reclined positions after subjects settled and the readings became stabilized.

We then removed the FSA Pressure Mapping System, secured the SFDL and the remaining sensors to the wheelchair, and started the logging program. Subjects were sent home and instructed to go about their ADL as usual for about 2 weeks.

\section{Midstudy Visit}

At the end of the first week, subjects either returned to the center or a research associate visited their home to check sensor placement, download data, and replace the SFDL batteries.

\section{Final Visit}

Subjects either returned to the center or a research associate visited their homes to remove the SFDL and its sensors. Subjects were also asked to complete a brief questionnaire regarding how often and how long they accessed the powered seating functions and under what circumstances they accessed these seating functions. We asked them to complete the questionnaire at the end of the study to ensure that responses did not influence their use of seating functions during the study period.

\section{Data Analysis and Reduction}

The data collection program running on the SFDL was written in TFBASIC from Onset Computer Corp (Bourne, Massachusetts). We used the pressure sensors sampled every 15 seconds to determine wheelchair occupancy. Readings from all the sensors and current time stamps were stored every 15 seconds in the SFDL if the subject was in the chair.

The data analysis and reduction program was written in MATLAB (The MathWorks Inc; Natick, Massachusetts), which read the data file downloaded from the SFDL and calculated all variables of interest of wheelchair occupancy, usage patterns of seating functions, and characteristics of usage patterns.

\section{Wheelchair Occupancy}

We calculated three variables related to wheelchair occupancy based on pressure sensor readings: total occupancy duration, duration of the longest single continuous occupancy, and transfer frequency. A transfer activity was counted whenever subjects left their wheelchairs for at least 10 minutes or returned to and stayed in the wheelchair for at least 2 minutes.

\section{Usage Patterns of Seating Functions}

Based on the sensitivity of the sensors and examination of the data from subjects, we established the following criteria for an access to tilt-in-space, backrest recline, and seat elevation. A tilt-in-space or backrest recline access was defined as an angle change $>2.5^{\circ}$ in either fore or aft directions and a duration of at least 1 minute. A seat-elevation access was defined as a position change $>1 \mathrm{~cm}$ in either direction with no duration threshold. Because the tilt sensors have a static fluctuation of approximately $\pm 1^{\circ}$ and could be perturbed by wheelchair vibration introduced by terrain changes and accidental movements of the subject, we developed a data reduction 
algorithm to filter the raw data. The algorithm searched for the peaks and valleys of the tilt-in-space or backrest recline angles, averaged the adjacent angles (peak or valley), and summed the durations if the difference was $<2.5^{\circ}$ or 1 minute.

Frequency of access to individual seating functions and duration of access to different seating positions were calculated, where an upright position was defined as a tilt-in-space angle $<2.5^{\circ}$ and a backrest recline angle $<95^{\circ}$. For both the tilt-in-space and backrest recline functions, the access frequency and duration to five ranges of tilt-in-space (i.e., $2.5^{\circ}-10^{\circ}, 10^{\circ}-20^{\circ}, 20^{\circ}-0^{\circ}, 30^{\circ}-40^{\circ}$, and $\geq 40^{\circ}$ ) and recline angles (i.e., $95^{\circ}-100^{\circ}, 100^{\circ}-110^{\circ}$, $110^{\circ}-120^{\circ}, 120^{\circ}-130^{\circ}$, and $\geq 130^{\circ}$ ) were also calculated.

\section{Characteristics of Usage Patterns}

The damaging effects of pressure to tissues are related to both its magnitude and duration [20-21], so two measures, including the repositioning rate and time spent in different magnitudes of interface pressure, were obtained to indicate usage characteristics. First, we obtained the repositioning rate by calculating the frequency of seating position changes. Second, based on clinical practice, seating interface pressures can be classified as low, intermediate, or high if they are $<80 \mathrm{mmHg}$, between 80 and 120 $\mathrm{mmHg}$, and $>120 \mathrm{mmHg}$, respectively [22]. To calculate the time spent in seating positions known to fall within the three categories, we compared actual seating positions recorded by the SFDL with the seating positions recorded during the pressure-mapping procedure. Because the interface pressure data were collected under the seating positions in $5^{\circ}$ increments during the pressure-mapping procedure and those seating positions with known interface pressure did not match exactly the actual seating positions recorded by the SFDL, an approximate match was considered if the distances between the seating positions recorded by the SFDL and evaluated during the pressure-mapping procedure were $<2.5^{\circ}$.

\section{Statistical Analysis}

Descriptive statistics, including mean \pm SD for continuous data and frequencies for categorical data, were calculated for all variables. We used nonparametric statistics to determine differences because the sample size was small. For specific aim 1 (discussed on page 974), we calculated a Wilcoxon signed rank test to determine if subjects spent more time in a tilted versus an upright position and if tilt-in-space was used significantly more than backrest recline and/or seat elevation. Using a Bonferroni correction, we set statistical significance at $p<$ 0.025 to account for using multiple tests on the same data and used a repeated-measures analysis of variance (ANOVA) to determine if durations and frequencies of access to five ranges of tilt-in-space and reclined angles differed significantly. For specific aim 2, we used a repeated-measures ANOVA to determine if the time spent in low, intermediate, and high peak pressure positions differed significantly. For specific aim 3, we used the intraclass correlation coefficient (ICC) to determine agreement between the actual and reported usage. All statistics were analyzed with SPSS Inc (Chicago, Illinois) statistical software.

\section{RESULTS}

\section{Demographics}

A total of 12 subjects were recruited to participate in the study, and results were reported for 11 subjects (data from the first subject was not used because of inconsistency). Participants included six men and five women with a mean age of $44.4 \pm 14.5$ years. Four different disability types were represented in this sample: 4 (36.3\%) subjects with SCI, 3 (27.3\%) with cerebral palsy (CP), 3 (27.3\%) with multiple sclerosis (MS), and 1 (9.1\%) with muscular dystrophy.

\section{Wheelchair Data}

Nine (81.8\%) participants used Permobil Inc (Lebanon, Tennessee) wheelchairs, and the remaining two (18.2\%) used power wheelchairs from Invacare Corp (Elyria, Ohio). The average age of these wheelchairs was $2.5 \pm 2.0$ years. All wheelchairs had the tilt-in-space function, nine had backrest recline function, and nine had seatelevation function. The tilt-in-space range was $0^{\circ}$ to $20^{\circ}$ for two wheelchairs and $0^{\circ}$ to $40^{\circ}$ or more for nine wheelchairs. The recline range was $90^{\circ}$ to $115^{\circ}$ for one wheelchair and $90^{\circ}$ to $130^{\circ}$ or more for eight wheelchairs.

\section{Wheelchair Occupancy}

On average, subjects occupied their wheelchairs for $11.8 \pm 3.4$ hours a day, with an average longest single occupancy of $10.6 \pm 3.6$ hours. Subjects transferred in and out of their wheelchairs for an average of $5.0 \pm 5.3$ times a day. 


\section{Seating Function Usage}

Figure 2 shows the average daily frequencies of access to tilt-in-space, backrest recline, and seat elevation for each subject. Figure 3 shows the percentage of time in each seating position by day, including tilted, reclined, simultaneously tilted and reclined, upright, and elevated. On average, subjects accessed tilt-in-space $19 \pm 14$ times and spent 64.1 percent of their time each day in tilted seating positions. Nine subjects accessed backrest recline $12 \pm 8$ times and spent 76 percent of their time each day in reclined seating positions. These nine subjects also chose to spend 39.3 percent of their time each day in tilted and reclined seating positions. Little time, i.e., $0.6 \pm$ 1.5 hours, was spent in a fully upright position each day. Seat-elevation usage was recorded for six subjects only, because three wheelchairs could not accommodate the

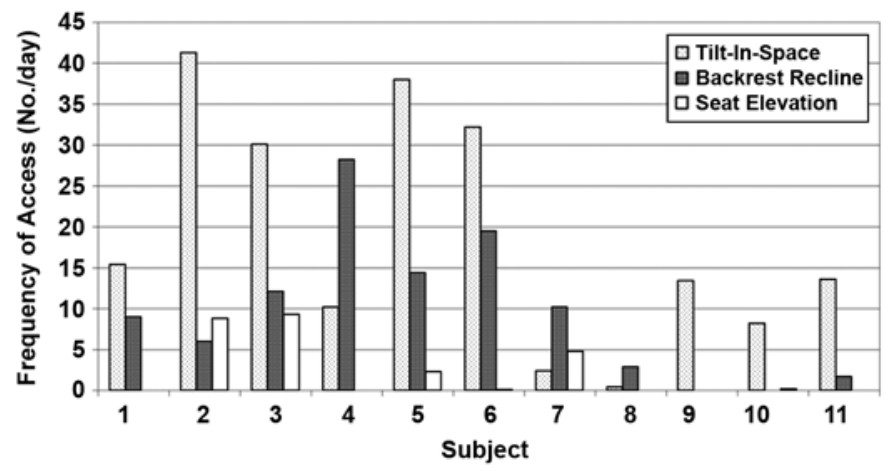

Figure 2.

Frequency of access each day to individual seating functions of 11 wheelchair users.

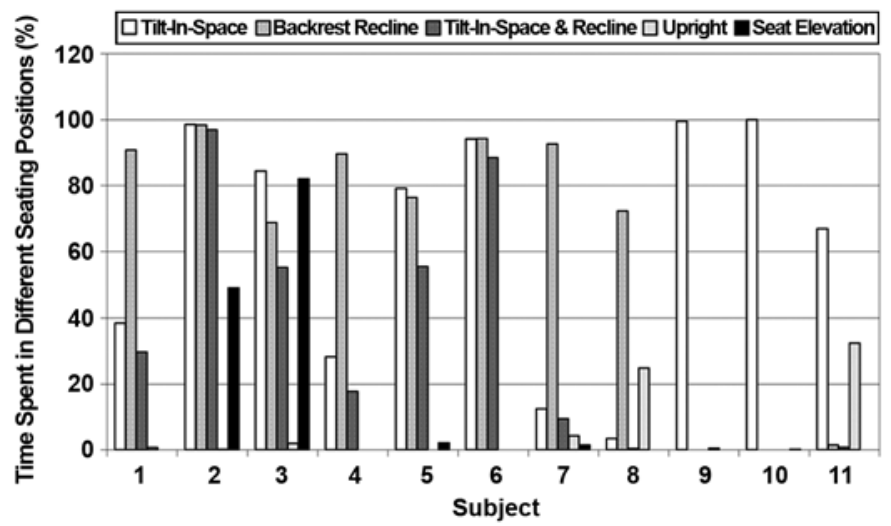

Figure 3.

Duration of access each day to different seating positions of 11 wheelchair users. linear position transducer because of space constraints. This function was accessed $4 \pm 4$ times for 22.5 percent of time each day. Results of the Wilcoxon signed rank test indicated that subjects spent significantly more time in a tilted versus an upright position $(p=0.006)$. In addition, we found that tilt-in-space was not used significantly longer than backrest recline $(p=0.59)$ or seat elevation $(p=0.03)$.

Tables 1 and 2 show the frequency and duration of access to five ranges in degrees of tilt-in-space and backrest recline angles, respectively. A repeated-measures ANOVA with Greenhouse-Geisser correction indicated that both the frequency $\left(F_{2.67,26.68}=7.78, p=0.001\right)$ and duration $\left(F_{1.57,15.74}=8.70, p=0.005\right)$ of access to the five ranges of tilt-in-space angles differed significantly. A Wilcoxon signed rank test further revealed that subjects accessed small tilt angles $\left(<20^{\circ}\right)$ more often $(13.8 \pm 9.9$ vs $4.7 \pm 5.9, p=0.003)$ and for longer durations (430.0 \pm $260.8 \mathrm{~min}$ vs $51.1 \pm 72.3 \mathrm{~min}, p=0.003$ ) than large angles. The same test also indicated that both the frequency $\left(F_{2.67}\right.$, $26.68=7.78, p=0.001)$ and duration $\left(F_{1.50,11.96}=6.04\right.$, $p=0.02$ ) of access to the five ranges of backrest recline angles differed significantly. Subjects accessed small recline angles $\left(<110^{\circ}\right)$ more often $(8.7 \pm 4.8$ vs $4.0 \pm 3.2$, $p=0.01)$ and for longer durations (442.7 $\pm 242.7 \mathrm{~min}$ vs $49.5 \pm 44.6 \mathrm{~min}, p=0.01)$ than large angles.

\section{Characteristics}

On average each day, subjects repositioned themselves every $53.6 \pm 47.0$ minutes. They sat for as long as $214.6 \pm 87.4$ minutes without changing seating positions. The minimum repositioning rate was about $6.1 \pm$ 14.8 minutes. Subjects spent $36.2 \pm 32.4,44.0 \pm 24.0$, and $19.9 \pm 29.4$ percent of their time in seating positions known to achieve low $(<80 \mathrm{mmHg})$, intermediate (between $80 \mathrm{mmHg}$ and $120 \mathrm{mmHg}$ ), and high peak pressure positions (>120 mmHg), respectively. The time spent in seating positions within the three categories did not significantly differ $(p=0.29)$.

\section{Survey Results}

Each day, subjects reported accessing the three functions tilt-in-space, backrest recline, and seat elevation $11.9 \pm 9.4,10.0 \pm 7.9$, and $4.3 \pm 4.5$ times, respectively. The reported frequencies on tilt-in-space and backrest recline seating functions were correlated with the actual results: $\mathrm{ICC}=0.63, p=0.004$, and ICC $=0.79, p=0.004$, respectively. The correlation between the reported and actual frequency on seat elevation was not statistically 
Table 1.

Tilt-in-space frequency and duration of access (in mean \pm standard deviation) for different ranges of angles of 11 wheelchair users.

\begin{tabular}{ccc}
\hline Angle ( $\left.{ }^{\circ}\right)$ & $\begin{array}{c}\text { Frequency } \\
(\mathbf{N o . / D a y})\end{array}$ & $\begin{array}{c}\text { Duration } \\
(\text { Min/Day) }\end{array}$ \\
\hline $2.5-10.0$ & $6.6 \pm 4.9$ & $272.7 \pm 228.7$ \\
$10-20$ & $7.3 \pm 6.6$ & $157.3 \pm 171.8$ \\
$20-30$ & $2.2 \pm 2.5$ & $24.6 \pm 37.8$ \\
$30-40$ & $0.9 \pm 1.2$ & $11.6 \pm 21.5$ \\
$>40$ & $1.6 \pm 4.1$ & $14.8 \pm 28.6$ \\
\hline \hline
\end{tabular}

Table 2.

Backrest recline frequency and duration of access (in mean \pm standard deviation) for different ranges of angles of 11 wheelchair users.

\begin{tabular}{rcc}
\hline Angle ( ${ }^{\circ}$ ) & $\begin{array}{c}\text { Frequency } \\
(\mathbf{N o . / D a y})\end{array}$ & $\begin{array}{c}\text { Duration } \\
\text { (Min/Day) }\end{array}$ \\
\hline $95-100$ & $2.1 \pm 2.6$ & $135.0 \pm 203.4$ \\
$100-110$ & $5.0 \pm 4.3$ & $227.2 \pm 231.2$ \\
$110-120$ & $2.0 \pm 2.0$ & $29.5 \pm 35.4$ \\
$120-130$ & $0.8 \pm 0.9$ & $6.2 \pm 9.8$ \\
$>130$ & $0.4 \pm 0.7$ & $4.8 \pm 11.2$ \\
\hline \hline
\end{tabular}

significant (ICC $=0.60, p=0.1$ ). The questionnaire also asked subjects to indicate their reasons for using the selfactuated seating functions. All subjects reported using tilt-in-space and/or backrest recline to adjust posture for comfort. In addition, about 70 percent of the subjects reported using tilt-in-space and/or backrest to relieve pressure on the buttocks. Seat elevation was reported to help reach things at higher levels, transfer, work at different levels, shop, sit at a bar, turn on-off light switches, go to the bathroom, socialize, eat, read the calendar on the refrigerator, and reach elevator buttons. Backrest recline was also reported to facilitate ADL, such as napping, self-catheterization, and leg stretches and/or exercises.

\section{DISCUSSION}

A full complement of self-actuated seating functions can easily double the cost of a power wheelchair; thus, researchers need to investigate the outcomes such seating functions can realistically deliver in the natural environment of wheelchair users. Inadequate seating systems or ineffective usage of such systems can extensively increase costs to treat pressure sores, chronic pain, fatigue, and unnecessary limitations to ADL $[6,9]$. This study was the first to investigate the real-life usage of powered seating functions that include tilt-in-space, backrest recline, and seat elevation. The information collected allows for a novel and quantitative examination of seating-function usage patterns and characteristics among power wheelchair users. Clinicians currently prescribe power wheelchairs with such seating functions primarily on the basis of clinical examination and consumer interviews, and they generally instruct clients during their short interactions on how to appropriately use the seating functions. They usually cannot track the usage and monitor the compliance after clients return home. The unobtrusive SFDL device and the methodology described in the study could enhance wheelchair provision clinical practice, resulting in better compliance and appropriate use among wheelchair users who are prescribed power wheelchairs with such seating functions.

Subjects in this study spent considerable time, i.e., $11.8 \pm 3.4$ hours a day, in their wheelchairs and performed only a limited number of transfers in and out of their wheelchair. This finding is similar to the result by Sonenblum et al. who found that power wheelchair users occupied their wheelchairs an average 10 hours a day [17]. Tolerico et al. also found that a group of manual wheelchair users were active for $12.0 \pm 3.6$ hours a day at the National Veterans Wheelchair Games and for $7.1 \pm$ 4.9 hours a day in their home environments [23]. Given the considerable amount of time wheelchair users spend in their wheelchairs, powered seating functions that allow for posture changes and pressure management are important for those who cannot independently adjust their positions or who are at risk for pressure ulcers.

We found that subjects in this study consistently accessed tilt-in-space and backrest recline throughout the day. They accessed tilt-in-space for an average of $19 \pm$ 14 times and spent 64.1 percent of their time each day in tilted seating positions. The access to backrest recline was found less frequently but slightly longer compared with tilt-in-space, i.e., $12 \pm 8$ times and 76.0 percent of their time each day in reclined seating positions. Subjects in the study spent very little time, i.e., $0.6 \pm 1.5$ hours a day, in a fully upright position. Comfort and postural factors may play active roles in the near-constant use of tilt-inspace and/or backrest recline among subjects. Maintaining a fully upright position is difficult for individuals with weakness and fatigue, because the trunk tends to fall forward when resting against a vertical surface [24]. Four subjects had a high-level SCI and therefore reduced trunk control, and three subjects had MS and were therefore 
susceptible to fatigue. Using tilt-in-space provides gravitational support to stabilize the upper body [24], thus, unsurprisingly, subjects in this study spent significantly more time in a tilted versus an upright position ( $p=$ 0.006). Subjects in the study also spent 39.3 percent of their time each day in tilted and reclined seating positions. Using a combination of such seating functions has been shown to reduce peak pressure more than using each individual function alone [4]. In addition, different combinations can lead to similar reductions in peak pressure [4], thus providing a large variety of seating positions from which wheelchair users can choose to maintain comfort, improve stability, and reduce seating pressure.

Subjects in this study tended to use small tilt-inspace angles (i.e., $<20^{\circ}$ ) based on both access frequency and duration. Lacoste et al. obtained similar findings in their survey study that individuals with a powered tilt-inspace seating function reported that they used small and medium angles more than large angles [11]. Sonenblum et al. also found that subjects spent the greatest amount of time in tilt-in-space angles $<20^{\circ}$ [17]. The fact that smaller angles of tilt-in-space were used possibly implies that this seating function was used more for functional and stable postures and comfort than for shifting weight or pressure management. Previous studies showed that comfort is a primary concern regarding the seating system and that people use smaller tilt-in-space angles to increase comfort [11,25]. Subjects in this study also reported that they accessed tilt-in-space to adjust posture for comfort. In previous studies, researchers found that a tilt-in-space angle of $\leq 15^{\circ}$ can be used to change back pressure distribution, but an angle $>15^{\circ}$ is necessary to achieve an effective weight shift [4]. In addition, maximum reductions in peak seating pressures occur when tilt-in-space angles are $\geq 45^{\circ}[4,7]$. Most subjects in this study did not choose to access tilt-in-space angles $40^{\circ}$ or higher for maximum pressure reduction. In addition to two wheelchairs that were not capable of achieving a tiltin-space angle of $\geq 40^{\circ}$, a possible reason could be the nonfunctional seating positions under large tilt-in-space angles. Of 11 subjects in the study, 8 were employed or attended school or organized daily programs; expecting them to use such nonfunctional positions frequently and for relatively longer durations is unrealistic. Subjects in this study also tended to access small recline angles (i.e., $<110^{\circ}$ ) more frequently than large angles. The most common recline angles on the basis of duration and frequency of accesses were generally between $100^{\circ}$ and $110^{\circ}$. This finding is similar to the previous findings by Lacoste et al. [11]. Backrest recline has been associated with shearing on the back [5,26-27], which is a risk factor for pressure ulcer development. A large recline angle is also undesirable in cases where instability is a problem [27]. In the Lacoste et al. survey study [11], wheelchair users indicated that they used backrest recline to increase comfort and rest. They also pointed out that they avoided large recline angles to prevent redness on their lower backs.

We used two measures, including the repositioning rate and time spent in positions of low, intermediate, and high pressures, to examine if subjects in this study used the seating functions effectively. Research has shown that the damaging effects of pressure to tissues are related to both its magnitude and duration. High loads for short durations and low loads for long durations can induce pressure ulcers with the time-at-pressure curve following one-half of an inverse parabola [20-21]. The clinical practice Guideline for Prevention and Management of Pressure Ulcer recommends that persons sitting for extended time periods reposition themselves every 15 minutes [28]. Subjects in this study repositioned themselves every $53.6 \pm 47.0$ minutes on average, and only one subject followed the recommendation. Furthermore, subjects may not reposition themselves for as long as 3.6 hours. No matter how small the amplitude of peak pressure under such seating positions, staying static for such long time periods is dangerous. In this study, subjects' own pressure profiles under different seating positions were used as references when the time spent in different pressure positions was calculated, because factors such as cushion type [29] and body build [30] could contribute to determining seating pressure profiles. The pressure-mapping procedure revealed that pressure distribution under different seating positions varied greatly between subjects. Previous studies found that differences in peak pressure diminish as body mass index increases [31-32]. Cushions also help reduce pressure on bony areas, but a good cushion alone is insufficient for adequate pressure relief [7]. Peak pressure was chosen here as a measure because of its frequent use in clinics for choosing seat cushions and identifying problem areas where pressure sores are likely to occur. Though previous studies have indicated that peak pressure is not a reliable or stable measure, it is more volatile than average pressure and can detect pressure differences between different seating positions easily [9,33-34]. Although the time 
spent in seating positions of low, intermediate, and high peak pressures did not significantly differ, most subjects in the study accessed low and intermediate peak pressure positions for longer time periods than high peak pressure positions.

Different from tilt-in-space and backrest recline, seat elevation facilitates the completion of ADL and offers psychosocial benefits to the user. A RESNA position paper on seat elevation put forth that seat elevators are just as necessary as tilt-in-space and backrest recline [2]. It listed transfers, reach, and eye-to-eye contact as essential usage of the seat-elevation function. Subjects in this study also reported similar reasons for using their seat elevators. Five out of nine subjects whose wheelchairs were equipped with seat-elevation functions reported using the seat elevator to reach things either at home, work, or in public; four reported using the seat elevator to reach higher levels, such as when working at different levels and sitting at a bar; and three reported using the seat elevator to facilitate transfers. Because seat elevation is used primarily to complete ADL, we found that, unsurprisingly, this function was used less frequently than tiltin-space and backrest recline.

One limitation of the study is the small sample size, and thus the result cannot be generalized and compared among groups with different characteristics. Individuals with SCI who have impaired sensation may have different usage patterns from those with motoneuron impairments such as CP and MS. A 2-week protocol is also relatively short and may not reliably capture typical usage patterns. Some limitations were related to the device and data reduction methods used in this study. The pressure sensors could not differentiate the occupancy of a human body from a pet or a heavy object, such as books on the seat, resulting in ambiguous data and a few repeated trials. The linear position transducer could not be mounted on the wheelchairs of three subjects because of space constraints, resulting in an important data loss. The thresholds that we used to determine the frequency of access to tilt-in-space, backrest recline, and seat elevation may not be optimal.

Future studies would benefit from more subjects from different geographic locations and with a wider variety of disabling conditions, a variety of wheelchair configurations on seating function usage, and a revised questionnaire requesting context information of seating function usage and pain conditions. Further investigation on the correlations between seating function usage and some ADL, such as transfers, could be conducted with a greater number of subjects. Also, measuring back-pressure distribution during the pressure-mapping procedure would be helpful. Possible improvements should be made to the existing SFDL as well. A different seat-elevation sensor needs to be selected that will accommodate as many wheelchairs as possible without sacrificing accuracy. The addition of sensors that can monitor the use of elevating leg rests, standing wheelchairs, or lateral tilt systems might be beneficial. Furthermore, the SFDL should be developed into a more robust technology for possible commercialization and/or clinical use.

\section{CONCLUSIONS}

The study provided an objective measure of usage patterns of wheelchair seating functions with a customized portable device. The ability to measure this information enables a better understanding of the real-world usage of these seating functions among a group of power wheelchair users for whom this information is very limited. We found that subjects consistently accessed the seating functions throughout the day and spent most of their time in tilted and/or reclined positions; however, most did not reposition themselves as frequently as recommended in the clinical practice guideline [28]. The information collected could enhance clinical practice of wheelchair provision, resulting in better compliance with clinical instructions and appropriate use of such seating functions among wheelchair users prescribed power wheelchairs.

\section{ACKNOWLEDGMENTS}

Shirley G. Fitzgerald, $\mathrm{PhD}$, is now with the Patient Safety Center at James A. Haley Veterans' Hospital, VA Medical Center, in Tampa, Florida.

This material was based on work supported by the Paralyzed Veterans of America Research Foundation, grant 2264-01; National Institute on Disability and Rehabilitation Research, grant H133F040006; and VA Rehabilitation Research and Development Center, grant B3142C.

The authors have declared that no competing interests exist. 


\section{REFERENCES}

1. Trefler E, Schmeler M. State of the science white paper on seating for postural control. In: Brubaker CE, Brienza, DM, editors. Proceedings of Wheelchair Seating: A State of the Science Conference on Seating Issues for Persons with Disabilities; 2001 Feb 19-20; Rehabilitation Engineering Center on Wheeled Mobility and the School of Health and Rehabilitation Sciences, Orlando, FL. Pittsburgh (PA): University of Pittsburgh; 2001. p. 21-26.

2. RESNA Position on the application of seat-elevating devices for wheelchair users [Internet]. Arlington (VA): Rehabilitation Engineering and Assistive Technology Society of North America [cited 2008 Oct 11]. Approved Sep 2005. Available from: http://www.rstce.pitt.edu/RSTCE Resources/Resna position on seat\%20elevation.pdf/.

3. Paralyzed Veterans of America. Pressure ulcer prevention and treatment following spinal cord injury: A clinical practice guideline for healthcare professionals. Washington (DC): Paralyzed Veterans of America; 2000.

4. Aissaoui R, Lacoste M, Dansereau J. Analysis of sliding and pressure distribution during a repositioning of persons in a simulator chair. IEEE Trans Neural Syst Rehabil Eng. 2001;9(2):215-24. [PMID: 11474974]

5. Hobson DA. Comparative effects of posture on pressure and shear at the body-seat interface. J Rehabil Res Dev. 1992;29(4):21-31. [PMID: 1432724]

6. Shields RK, Cook TM. Effect of seat angle and lumbar support on seated buttock pressure. Phys Ther. 1988;68(11): 1682-86. [PMID: 3186795]

7. Henderson JL, Price SH, Brandstater ME, Mandac BR. Efficacy of three measures to relieve pressure in seated persons with spinal cord injury. Arch Phys Med Rehabil. 1994; 75(5):535-39. [PMID: 8185445]

8. Sprigle S, Sposato B. Physiologic effects and design considerations of tilt and recline wheelchairs. Orthop Phys Ther Clin North Am. 1997;6(1):99-122.

9. Stinson M, Porter A, Eakin P. Measuring interface pressure: a laboratory-based investigation into the effects of repositioning and sitting. Am J Occup Ther. 2002;56(2): 185-90. [PMID: 11905303]

10. Coggrave MJ, Rose LS. A specialist seating assessment clinic: changing pressure relief practice. Spinal Cord. 2003; 41(12):692-95. [PMID: 14639449]

11. Lacoste M, Weiss-Lambrou R, Allard M, Dansereau J. Powered tilt/recline systems: why and how are they used? Assist Technol. 2003;15(1):58-68. [PMID: 14760982]

12. Crane BA, Holm MB, Hobson D, Cooper RA, Reed MP, Stadelmeier S. Development of a consumer-driven Wheelchair Seating Discomfort Assessment Tool (WcS-DAT). Int J Rehabil Res. 2004;27(1):85-90. [PMID: 15097177]
13. De Looze MP, Kuijt-Evers LF, Van Dieën J. Sitting comfort and discomfort and the relationships with objective measures. Ergonomics. 2003;46(10):985-97. [PMID: 12850935]

14. Goossens RH, Teeuw R, Snijders CJ. Sensitivity for pressure difference on the ischial tuberosity. Ergonomics. 2005; 48(7):895-902. [PMID: 16076744]

15. Cooper RA, Boninger ML, Cooper R, Fitzgerald SG, Kelleher A. Preliminary assessment of a prototype advanced mobility device in the work environment of veterans with spinal cord injury. NeuroRehabilitation. 2004;19(2):161-70. [PMID: 15201475]

16. Lankton S, Sonenblum SE, Sprigle S, Wolf J, Oliveira M. Use of GPS and sensor-based instrumentation as a supplement to self-report in studies of activity and participation. Poster session presented at: Proceedings of the Rehabilitation Engineering and Assistive Technology Society of North America (RESNA) Conference; 2005 Jun 23-27; Atlanta, GA.

17. Sonenblum SE, Sprigle S, Maurer C. Monitoring power upright and tilt-in-space wheelchair use. Poster session presented at: Proceedings of the Rehabilitation Engineering and Assistive Technology Society of North America (RESNA) Conference; 2006 Jun 22-26; Atlanta, GA.

18. Ding D, Cooper RA, Cooper R, Kelleher A. Monitoring seat feature usage among wheelchair users. Conf Proc IEEE Eng Med Biol Sci. 2007;2007:4364-67. [PMID: 18002970]

19. Fitzgerald SG, Kelleher A, Teodorski E, Collins DM, Boninger ML, Cooper RA. The development of a nationwide registry of wheelchair users. Disabil Rehabil Assist Technol. 2007;2(6):358-65.

20. Kosiak M. Etiology and pathology of ischemic ulcers. Arch Phys Med Rehabil. 1959;40(2):62-69. [PMID: 13618101]

21. Reswick J, Rogers J. Experience at Rancho Los Amigos Hospital with devices and techniques to prevent pressure sores. In: Kenedi RM, Cowden JM, Scales JT, editors. Bedsore biomechanics. Baltimore (MD): University Park Press; 1976. p. 301-10.

22. Shapcott N, Levy B. By the numbers: Making the case for clinical use of pressure measurement mat technology to prevent the development of pressure ulcers. TeamRehab Rep. 1999;16-18;20-21.

23. Tolerico ML, Ding D, Cooper RA, Spaeth DM, Fitzgerald SG, Cooper R, Kelleher A, Boninger ML. Assessing mobility characteristics and activity levels of manual wheelchair users. J Rehabil Res Dev. 2007;44(4):561-72. [PMID: 18247253]

24. Engström B. Ergonomic seating. A true challenge: seating and mobility for the physically challenged: risks \& possibilities when using wheelchairs. Värmdö (Sweden): Posturalis Books; 2002. p. 40-43. 
25. Weiss-Lambrou R, Tremblay C, LeBlanc R, Lacoste M, Dansereau J. Wheelchair seating aids: How satisfied are consumers? Assist Technol. 1999;11(1):43-53.

26. Pope PM. A study of instability in relation to posture in the wheelchair. Physiotherapy. 1985;71(3):124-28.

27. Gilsdorf P, Patterson R, Fisher S, Appel N. Sitting forces and wheelchair mechanics. J Rehabil Res Dev. 1990;27(3): 239-46. [PMID: 2401955]

28. Pressure ulcer prevention and treatment following spinal cord injury: a clinical practice guideline for health-care professionals. J Spinal Cord Med. 2001;24 Suppl 1:S40-101. [PMID: 11958176].

29. Koo TK, Mak AT, Lee YL. Posture effects on seating interface biomechanics: comparison between two seating cushions. Arch Phys Med Rehabil. 1996;77(1):40-47. [PMID: 8554472]

30. Stinson MD, Porter-Armstrong AP, Eakin PA. Pressure mapping systems: reliability of pressure map interpretation. Clin Rehabil. 2003;17(5):504-11. [PMID: 12952156]
31. Kernozek TW, Wilder PA, Amundson A, Hummer J. The effects of body mass index on peak seat-interface pressure of institutionalized elderly. Arch Phys Med Rehabil. 2002; 83(6):868-71. [PMID: 12048670]

32. Garber SL, Krouskop TA. Body build and its relationship to pressure distribution in the seated wheelchair patient. Arch Phys Med Rehabil. 1982;63(1):17-20.

[PMID: 7055413]

33. Clarke HF, Bradley C, Whytock S, Handfield S, Van der Wal R, Gundry S. Pressure ulcers: implementation of evidencebased nursing practice. J Adv Nurs. 2005;49(6):578-90. [PMID: 15737218$]$

34. Sprigle S, Dunlop W, Press L. Reliability of bench tests of interface pressure. Assist Technol. 2003;15(1):49-57. [PMID: 14760981]

Submitted for publication November 5, 2007. Accepted in revised form May 12, 2008. 